\title{
Resistance of Conifer Needle Polyolefin Composites (CNPCs) Against Biodecomposition Caused by Fungi
}

\author{
Joanna Barton-Pudlik ${ }^{1} \cdot$ Krystyna Czaja $^{1} \cdot$ Jacek Lipok $^{1}$
}

Published online: 11 May 2017

(C) The Author(s) 2017. This article is an open access publication

\begin{abstract}
This study describes the resistance of composites filled with conifer needles to biodecomposition processes caused by a single strain of Aspergillus niger as well as by a consortium of microorganisms present in the compost substrates (forest or spent mushroom composts). The impact of various types of conifer needles on the growth of A. niger was studied to determine whether the filler can show the fungistatic effect. The changes in chemical composition of the composites surfaces were examined using attenuated total reflectance Fourier transform infrared spectroscopy (FTIR/ATR). The results showed that the fungistatic effects of conifer needles polyolefin composites (CNPCs) were associated with type, content and fragmentation of fillers. The most effective were composites that contained 30 or $50 \mathrm{wt} \%$ of pine or spruce needles flour, since respectively the mycelial growth was inhibited by approximately $50 \%$, or totally. Moreover, the 90 days experiment conducted in the forest compost showed that the addition of $50 \mathrm{wt} \%$ mercerized conifer needles and 10 wt $\%$ natural resin increased the resistance to biodecomposition for about $40 \%$ in comparison with composite containing unmodified needles. Even higher about $60 \%$ increase in resistance was observed comparing to sample with mercerized filler. In turn in the spent mushroom compost, these differences amounted respectively to 50 and $78 \%$, what confirmed that the addition of natural sources of resin established a protective barrier against the impact of examined fungus.
\end{abstract}

Joanna Barton-Pudlik

jbarton@uni.opole.pl

1 Faculty of Chemistry, Opole University, Oleska 48, 45-052 Opole, Poland
Keywords Conifer needles $\cdot$ Polymer composite . Aspergillus niger $\cdot$ Composting $\cdot$ Spent mushroom compost

\section{Introduction}

In recent years polymer composites with renewable plant fillers have been quickly developing as new materials. This is due to the fact, that they offer many favourable properties $[1,2]$ and they are more environmentally friendly (renewability of raw material plants). Since polymer composites are used in various areas of the economy, it is important to determine durability of such materials, in particular in terms of the impacts of environmental factors, including microorganisms.

The literature mentions two different research strategies of conducting biodegradation tests. The first one involves using pure strains able to degrade polymer composites [3-6]. However, the processes occurring in the natural environment result from a synergistic interaction of various environmental factors. For this purpose, the second approach assumes studies on biodegradation involving microbial communities for example in marine water, soil or compost [3, 7-9]. The mechanism of biodegradation involves using polymer composites as a source of carbon and energy by microorganisms [10-12]. A series of testing methods has been developed for biodegradation testing. One of them can be successfully used in the biodegradation detection e.g. scanning electron microscopy (SEM), weight loss or respirometry (for mineralization indicate) [13-15]. Others can also evaluate the effects and degree of biodegradation caused by microorganism growth e.g. electrochemical impedance spectroscopy (EIS), gel permeation chromatography (GPC) or proton magnetic resonance $\left({ }^{1} \mathrm{H}\right.$ NMR) $[8,10,16]$. 
Wood-polymer composites (WPC) make the most famous examples among the group of composites with the plant material content. On the one hand, there are studies that have shown the examples of WPCs and have indicated that the polymer matrix can completely encapsulate the wood filler particles and therefore protect them against biodegradation [17]. On the other hand, there are studies that suggest that the WPCs biodegradation process starts from biodecomposition of the plant filler particles, and it is dependent on plant species and on microbial activity [18, 19]. Lomelí-Ramírez et al. [20] indicated that WPCs which contained pine wood flour were less susceptible to the fungal attack than WPCs which had been filled with oak or maple flour. In turn, Xu et al. [21] described the effects of volatile chemical components of various wood species on mould resistance of wood-plastic composites. The author also showed the fungistatic effect of the extract obtained from softwood flour (caryophyllene, $\alpha$-pinene, (Z)-13-docosenamide). The results of those studies indicated that the composites that contained a conifer plant material offered superior resistance.

Wood fillers mainly consist of cellulose, hemicellulose and lignin, and a small amount of extractives. The main type of extractives are resins, fats and polyphenols [22]. These extractives may be responsible for the increased or reduced resistance of the composite material to the microbial attack. The conifer needles make the example of a plant filler that contains a higher amount of extractives than wood flour [23]. Berg et al. [24] described the composition of green pine needles. The study showed that solid phase (65.4\%) mainly consisted of carbohydrate and lignin, while the extractives $(41.1 \%)$ consisted of the fractions which were: light petroleum soluble $(29.7 \%)$, ethyl acetate soluble (12.2\%), 2-butanone soluble $(9.7 \%)$ and water soluble $(48.4 \%)$. What is more, the authors tested the effects of those extracts on the growth of several fungal species and they indicated that growth of the most of the tested fungal strains was inhibited, especially by the ethyl acetate soluble fraction. In turn, Sharma et al. [25] presented the results of degradation of pine needles caused by Aspergillus niger under solid state fermentation conditions that shows that pine needles are resistant to the impact of mycelium. However, pine needles subjected to alkali pretreatment can be successfully degraded. On the other hand, there are known examples in the literature that show the ability of certain microorganisms to degrade extractive constituents [22,26].

Previously [27] we described the possibility of using various conifer needles as fillers in a polyolefin matrix. It was decided in this study to investigate the resistance of composites with conifer needles (CNPCs) to biodecomposition processes. According to the studies by Flemming [28] or Catto et al. [29], the essential step in carrying out the biodegradability tests of multi-component materials (like CNPCs) is the selection of a suitably active group of microorganisms which possess the ability to biodegrade at least one of the components. Therefore, influence of the presence of composites that contained particles, or flour, of conifer needles on the development of A. niger mycelium was tested as the first step. Based on the obtained results, the addition of natural resins as the substances that could potentially improve the fungistatic effect was proposed. Thus, the fungistatic effect of four commercially available natural resins on A. niger was studied. In the final stage, in order to assess the resistance of CNPCs (with, or without natural resin) to biodecomposition processes, the composting was carried out in two different systems; in forest or in spent mushroom compost. The experiments were a kind of mimics of natural processes.

\section{Materials and Methods}

\section{Materials}

The materials used in this study were the composites with the PEHD matrix (Purell GC 7260, MFR $=8 \mathrm{~g} / 10 \mathrm{~min}$ $\left(190^{\circ} \mathrm{C}, 2.16 \mathrm{~kg}\right)$, density $\left.0.963 \mathrm{~g} / \mathrm{cm}^{3}\right)$, PELD matrix (Lupolen 1800S, MFR $=20 \mathrm{~g} / 10 \mathrm{~min}\left(190^{\circ} \mathrm{C}, 2.16 \mathrm{~kg}\right.$ ), density $0.917 \mathrm{~g} / \mathrm{cm}^{3}$ ), PP matrix (Moplen HP400R, $\mathrm{MFR}=25 \mathrm{~g} / 10 \mathrm{~min}\left(230^{\circ} \mathrm{C}, 2.16 \mathrm{~kg}\right)$, density $0.900 \mathrm{~g} /$ $\mathrm{cm}^{3}$ ), and propylene-ethylene copolymer, co(E-P) matrix (Moplen EP540P, MFR $=15 \mathrm{~g} / 10 \mathrm{~min}\left(230^{\circ} \mathrm{C}, 2.16 \mathrm{~kg}\right.$ ), density $0.900 \mathrm{~g} / \mathrm{cm}^{3}$ ). The natural conifer filler was prepared from pine $(\mathrm{P})$, thuja $(\mathrm{T})$, spruce $(\mathrm{S})$ and fir $(\mathrm{F})$ particles or it was sieved to the diameter $<500 \mu \mathrm{m}$. The filler was previously dried at $70^{\circ} \mathrm{C}$ for $12 \mathrm{~h}$ to remove most of water. The commercialy available natural resins, such as dammar gum (obtained from trees of the family Dipterocarpaceae), galbanum (aromatic oleo-gum-resin obtained from Ferula gummosa), rosin (obtained from conifer plants) and sandarac (obtained from cypress plants) were used in our studies.

The materials which contained: 10,30 or $50 \mathrm{wt} \%$ of different conifer needles were used in our experiments on susceptibility of CNPCs to A. niger. The plates of CNPCs which were $1 \mathrm{~mm}$ thick were prepared in a two-stage process, i.e. through initial mixing in the Hakke mixer and then they were formed in a hydraulic press. The samples of neat PEHD, PELD, PP, co(E-P) were submitted to the same treatment and used as reference pieces. We shared obtained the amount of each type of composite samples into two series. Series I was used in experiments immediately after preparation of composite samples. Series II was used after 4 weeks of their production. In turn, the studies on composting were based on HDPE composites which contained 30 or $50 \mathrm{wt} \%$ of conifer needles (modified through 
mercerization with, or without, the addition of $10 \mathrm{wt} \%$ natural resin). These materials were prepared in a laboratory (mini) twin screw extruder at the temperature profile of $155-170{ }^{\circ} \mathrm{C}$ and at the screw speed of $70 \mathrm{rpm}$, and then the test pieces were obtained injection moulding. Neat PEHD was used as reference (Table 1).

\section{Microorganisms and Microbial Media used for Material Biodegradation}

The studies were basically divided into two stages. During the first one, the composites with the particles or flour of conifer needles were exposed to the mycelium of Aspergillus niger (A. niger) (obtained from CCM-Czech Collection of Microorganisms). Pure cultures of filamentous fungi were necessary to conduct experimental cultivations. To obtain them, the preservative cultures, which were incubated at $28^{\circ} \mathrm{C}$ for about 2 weeks were used. In order to maintain culture continuity, the mycelium was transferred to a fresh medium within 2 weeks. The cultures were grown on the full liquid Czapek medium in a $100 \mathrm{ml}$ Erlenmeyer flask or on solid media (Czapek media solidified with agar) in Petri dishes.

Table 1 Sample ID and formulation of composite

\begin{tabular}{lll}
\hline Sample ID & Formulation & \\
\cline { 2 - 3 } & Matrix & Filler \\
\hline PELD with pine needles & & \\
PELD_P/10 & 90 & 10 \\
PELD_P/30 & 70 & 30 \\
PELD_P/50 & 50 & 50 \\
PEHD with thuja needles & & \\
PEHD_T/10 & 90 & 10 \\
PEHD_T/30 & 70 & 30 \\
PEHD_T/50 & 50 & 50 \\
PEHD with pine needles & & \\
PEHD_P/30* & 70 & 30 \\
PEHD_P/50* & 50 & 50 \\
PEHD_P/50m* & 50 & 50 \\
PEHD_P/50mr* & 50 & 50 \\
co(E-P) with spruce needles & & 10 \\
co(E-P)_S/10 & 90 & 30 \\
co(E-P)_S/30 & 70 & 50 \\
co(E-P)_S/50 & 50 & \\
PP with fir needles & & \\
PP_F/10 & 90 & \\
PP_F/30 & 50 & \\
PP_F/50 & & \\
\hline
\end{tabular}

*After composting in forest compost (k) or spent mushroom compost $(\mathrm{t})$, filler after mercerization (m), the addition of $10 \mathrm{wt} \%$ resin (r)
In the second stage of the study, composting tests of various composites were conducted in two types of compost: in 2 years old forest compost prepared and maturing in the pine forest, or in spent mushroom compost obtained as a waste product of the mushroom (Agaricus bisporus) industry.

\section{Methods}

\section{Cultures Grown in Liquid Media}

The microbiological cultures involving A. niger were taken for the test portion (weighted portion) of about $1 \mathrm{~g}$ of the composites in the form of plates. To prepare the spore suspension the 2-week old fungal cultures were used. The suspension was prepared by washing spores from the mycelium surface, using approx. $10 \mathrm{ml}$ of $0.01 \%$ sterile aqueous solution of Tween. The spore suspension was filtered through sterile gauze and then it was examined microscopically for spore density. The suspension was diluted, when necessary, to obtain the density of $10^{6}$ spores per $1 \mathrm{ml}$ of solution. The cultures were grown for 14 days in three repetitions each, and after that time the contents of the flasks were filtered through pre-weighed paper filters. Then, the filters were left in the laboratory oven at $60^{\circ} \mathrm{C}$ for $24 \mathrm{~h}$ to pre-dried. Afterward, they were dried at $62^{\circ} \mathrm{C}$ in moisture analyzer to obtain constant weight. Based on the balance of the mycelium weight, the gain was counted.

\section{Cultures Grown in Solid Media}

The experiments to check the fungistatic activity of selected natural resins (dammar gum, galbanum, rosin, and sandarac) towards A. niger ware carried out in aseptic Petri dishes using the standard agar-solidified Czapek medium. The experiments were established in the sterile medium $\left(20 \mathrm{~cm}^{3}\right)$. The resin solutions were prepared with various solvents, i.e. chloroform (dammar gum) and acetone or ethanol (galbanum, rosin, sandarac). The paper discs were soaked with $0.4 \mathrm{~cm}^{3}$ the respective solutions. The test samples, i.e. paper discs soaked in the solutions of appropriate resins $(0.25 ; 0.5 ; 1 ; 3 ; 5 ; 7 ; 10$ and $30 \%)$ were placed concentrically on the media surfaces (solid Czapek medium). Then, about $1 \mathrm{~cm}^{3}$ of inoculum (suspension of the spores of the test fungus) was distributed throughout the surface. The concentration of spores in the inoculum amounted to $10^{6} \mathrm{cfu} / \mathrm{cm}^{3}$. The Petri dishes were closed in order to reduce any possible microbial contamination. Each experiment was carried out for 2 weeks in three repetitions. Based on the macroscopic observation - visual inspection of the mycelial growth, in relation to the corresponding control sample (not soaked paper disc) and the reference sample (paper disc soaked in a solvent 
in which a resin solution was prepared), the susceptibility of the test material to colonisation by A. niger was determined.

\section{Composting}

The forest compost or spent mushroom compost was packed loosely in a polyethylene box, with the bed up to $80 \%$, under indoor conditions. All bioreactors were maintained at $60 \%$ of the water holding capacity. The samples in the form of beams or dumbbells were put vertically in the substrate so that their surface was covered completely. Three repetitions were performed for pure polymer (reference sample) and each type of composite. The reactors which contained spent mushroom compost were left at room temperature, while the containers with the forest compost were conditioned at $58^{\circ} \mathrm{C}$. To confirm microbial activity in both compost environment we used a piece of cotton as a control sample. The composting experiment lasted 3 months. After 90 days of exposure, the CNPCs samples were removed and washed with water. Then, for disinfection purposes, the samples were put for $10 \mathrm{~min}$ into a beaker containing the $30 \%$ solution of $\mathrm{H}_{2} \mathrm{O}_{2}$, and then they were washed again with water. The samples were dried to constant mass in a drying oven at $45^{\circ} \mathrm{C}$.

\section{Weight loss study}

After 3 months of incubation in the forest compost or spent mushroom compost, the samples (beams and dumbbells) were taken out and washed thoroughly with distilled water and ethanol. Then they were dried till the constant weight was reached. The formula to assess the weight loss was:

$\%$ weight loss $=\left(\mathrm{W}_{\mathrm{i}}-\mathrm{W}_{\mathrm{f}}\right) / \mathrm{W}_{\mathrm{i}} \times 100 \%$

where $\mathrm{W}_{\mathrm{i}}$ is the initial weight, $\mathrm{W}_{\mathrm{f}}$ is the final weight.

Neat PEHD was considered as the control sample.

\section{Morphological Characterization}

After exposure to fungal mycelium or composting, all the samples were visually inspected in order to detect any change in colours or crazing that can directly be linked to the occurrence of surface degradation.

For morphological characterization, samples were analysed with the scanning electron microscope (SEM) Hitachi TM 3000. The samples were coated with a thin film of gold in a sputter coater in order to eliminate electron charging and then observed at different resolutions using the voltage of $15 \mathrm{kV}$.

\section{FTIR/ATR}

The attenuated total reflectance Fourier transform infrared (FTIR/ATR) spectroscopy was used to investigate the chemical changes of composites with respect to the influence of biodegradation. The spectra were taken in the wavenumber range of $400-4000 \mathrm{~cm}^{-1}$ using the Nicolet 6700 Thermo Scientific instrument with the Smart Itr. accessory. Each sample was measured at three randomly chosen points, taking the mean value as the final result.

\section{Characterization of Properties}

The tensile strength, impact strength and melt flow rate were determined. The tensile tests were carried out under standard conditions [ISO 527-2 (1998)]. Five specimens from each composition were tested using an Instron tensometer (Norwood, Massachusetts, USA) equipped with a load cell of maximum capacity of $1 \mathrm{kN}$, operating at a grip separation speed of $100 \mathrm{~mm} / \mathrm{min}$. The Charpy impact strength was measured using a Zwick/Roell HIT 50P (Ulm, Germany) under standard conditions [ISO 179-1 (2010)]. The melt flow rate (MFR) was measured using a Zwick/ Roell Aflow extrusion plastometer type BMF-005 (Ulm, Germany), in accordance with ISO 1133-1 (2011).

\section{Results and Discussion}

The subject of the study was to test biodegradability of composites with the content of various types of conifer needles (pine, thuja, spruce, fir) in the form of particles of size $<10 \mathrm{~mm}$, or powdered $(<500 \mu \mathrm{m})$. The first stage of the study was to determine the impact of the presence of composites with different types of conifer needles on the growth of the A. niger mycelium. The research was conducted in a culture system on the Czapek liquid medium. Then, the impact of natural resins on the growth of A. niger was examined. The studies were carried out in Czapek media solidified with agar. The final stage included composting tests which were performed for selected materials together with the assessment of changes in their properties.

\section{Growth of the A. niger Mycelium Depending on the Composition of Polyolefin Composites Containing Conifer Needles}

Our studies used composites that contained a 10,30 or 50 wt $\%$ of particles obtained from pine, thuja, spruce or fir needles, or flour (pine, thuja, spruce). As it is known from the literature, the use of a large proportion by weight of the plant filler involves a significant deterioration of mechanical properties of the material $[30,31]$. Therefore, in the 
first step we present micrographs of the sample surfaces that were taken to assess superficial changes in the sample materials. Figure 1 shows examples of the results for co(E-P)_S $/ 50$ (series I) before and after 2 weeks exposure to the microbial medium culture. No significant changes were observed in the surfaces of the composites filled with particles and flour of spruce needles. Increased accessibility of the filler particles and deterioration of the composite surface smoothness were only found.

The weight gain results of the A. niger mycelium in the cultures grown on the liquid Czapek medium after 2 weeks (series I) are shown in Fig. 2. In the presence of the reference polyolefin samples [PELD, PEHD, co(E-P), PP] the mycelium weight gain was close to that for the control sample (containing no plant materials). For composite samples with conifer needle particles (red bars chart) at 10-30 wt $\%$, no significant changes were observed in the intensity of the mycelial weight, with respect to both the control sample and the reference samples. In turn, the presence of composites with $50 \mathrm{wt} \%$ of conifer needle particles limited the growth of $A$. niger. A slightly different result was obtained for the composites with the flour of conifer needles, i.e. in the case of composites containing powdered pine and spruce needles, it was observed that for such a low content as $10 \mathrm{wt} \%$ the mycelium weight gain was limited by $46.7 \%$ for PELD_P/10 and by $35.6 \%$ for co(E-P)_S/ 10 . Similarly, for composites with 30 and $50 \mathrm{wt} \%$ of the filler, the weight gain of A. niger was lower in comparison to the control and reference samples. PELD_P/30 grew by $49.4 \%$, co(E-P)_S $/ 30$ by $47.6 \%$, whereas the growth of fungus in the sample of co(E-P)_S $/ 50$ was entirely inhibited in practice. In turn, the presence of composites which contained the thuja flour (as in the culture systems with composites containing thuja particles) limited the mycelial growth only in the case of the $50 \mathrm{wt} \%$ filler content (approx. 46\%). The results indicate that the fungistatic effect grows with the increase of fragmentation (better distribution (less agglomeration) of the filler in the polymer matrix) and content of the filler particles. Moreover, the study evidenced the impact of the filler type on its ability to inhibit the growth of the A. niger mycelium-namely, the addition of pine and

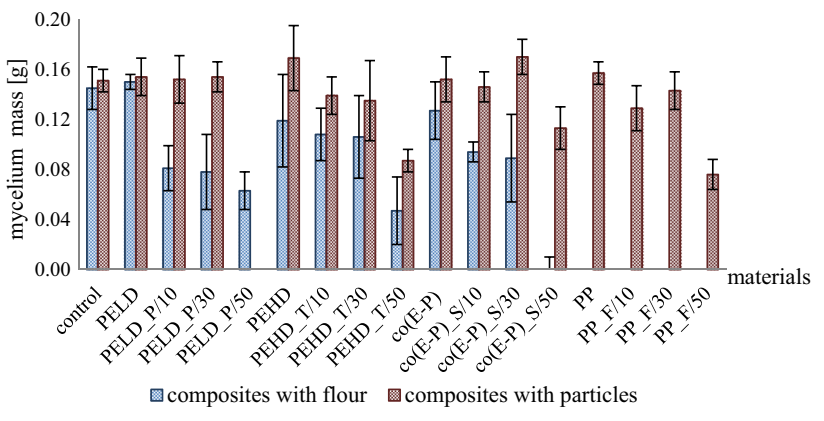

Fig. 2 Weight gain of $A$. niger mycelium cultured for 2 weeks in liquid Czapek medium in the presence of various types of composites (series I) with additives of conifer needles in the form of particles (red bar graphs) or flour (blue bar graphs). (Color figure online)

spruce needles in composites showed the greatest fungistatic effect, and on the contrary, the smallest/marginal effect was demonstrated by the addition of thuja needles.

Conifer needles contain significant amounts of extractives, cellulose, hemicellulose and smaller amounts of lignin [23]. Given the chemical composition of conifer needles, it can be expected that the observed fungistatic effect corresponds to the presence of resinous substances that contain mainly turpentine (volatile fraction-mostly monoterpene olefins with some sesquiterpenes) and rosin (non-volatile fraction-mostly resin acids) [32, 33]. The antimicrobial activity of both these fractions was indicated in numerous studies e.g. Ulukanli et al. [34] describes chemical compositions and antimicrobial activity of the essential oils belonging to Pinus pinea and Pinus brutia (main components- $\alpha$-pinene, $\beta$-pinene and D-Limonene 1,4-methenoazulene and caryophyllene). Tiitta et al. [35] revealed that there is a significant relation between the volatile organic compounds (mainly terpenes) and the mould resistance. In turn, the study by Franich et al. [36] describes the fungistatic effect of oxidized resin acids obtained from Pinus tradiata needles, and the studies by SavluchinskeFeio et al. [37-39], (1997, 1999, 2002), Kopper et al. [40], and Söderberg et al. [41] describe the antimicrobial activity of resin acid.

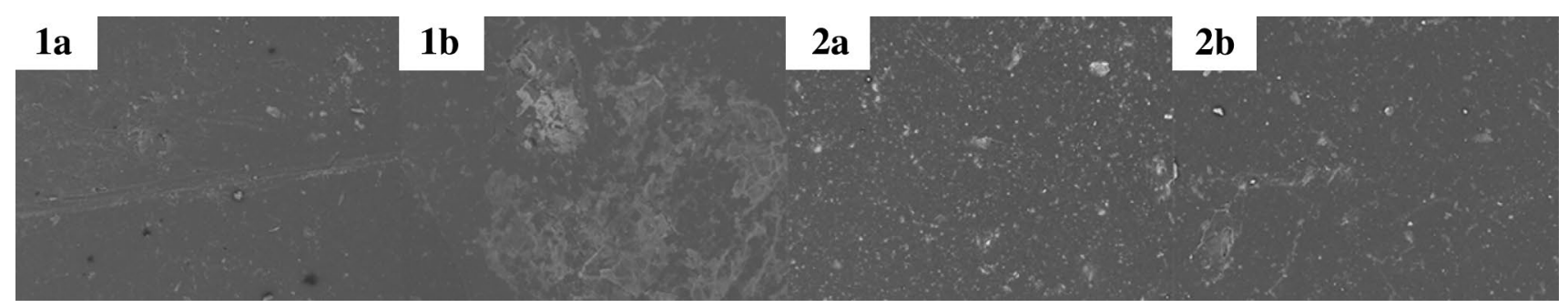

Fig. 1 Micrographs of the surface of the co(E-P)_S/50 composites (magnification of $\times 200$.) containing the filler particles $(a)$ or flour $(b)$ for the control sample (1), samples after the microbial medium culture (2) 
Due to the fact that some resin compounds are volatile, it was assumed that the observed effect may be weakened over time. Thus, the composites with the greater fungistatic impact, i.e. those containing flour of needles, were re-investigated after 4 weeks from the date of sample preparation (series II). In contrast to the previous culture, no inhibition

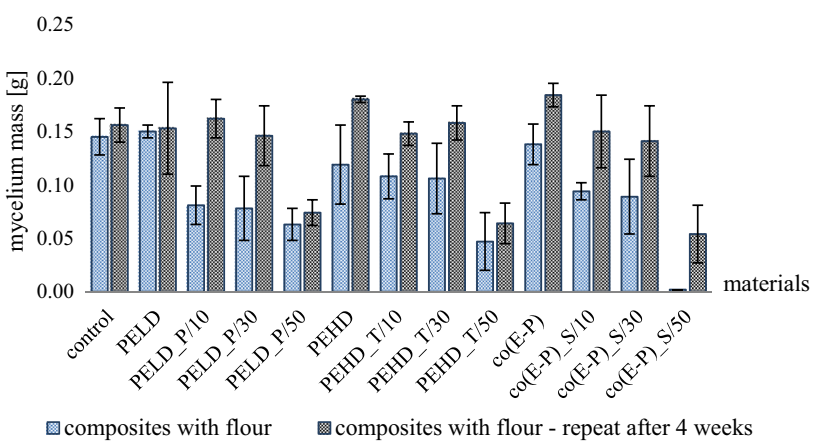

Fig. 3 Weight gain of $A$. niger mycelium cultured for 2 weeks in liquid Czapek medium in the presence of various types of composites with additives of conifer needles flour used immediately after production (series I blue bar graphs) and after 4 weeks from the date of production (series II black bar graphs). (Color figure online) of mycelial growth was observed for composites with 10 or $30 \mathrm{wt} \%$ of pine and spruce needles (Fig. 3). However, this effect was visible for all types of composites with $50 \mathrm{wt} \%$ of fillers. It confirmed the assumption that the compounds that are volatile were mainly responsible for inhibition of the mycelial growth. Moreover, the temporary inhibiting effect on the growth of mycelium was provided only by a high content of coniferous flour.

In our previous paper [19] we described structural changes that resulted from the impact of A. niger on the composites that contained various kinds of wood flour (coniferous, cellulose, deciduous). It was concluded that the smallest structural changes associated with the progress of the biodegradation process were observed for the composites which contained coniferous flour. In the next step, also for the composites with conifer needles the FTIR/ATR analysis was performed to characterise the changes in the intensities of the bands recorded for the composite. Figure $4 \mathrm{a}$ shows the difference between the spectrum obtained for the composite (series I) before and after the growth of $A$. niger. It can be observed, that among the bands which are typical for a plant filler (i.e. at $\left.3600-3000 \mathrm{~cm}^{-1}\right)$ and particularly in the fingerprint area $\left(1800-800 \mathrm{~cm}^{-1}\right)$ [42-44]

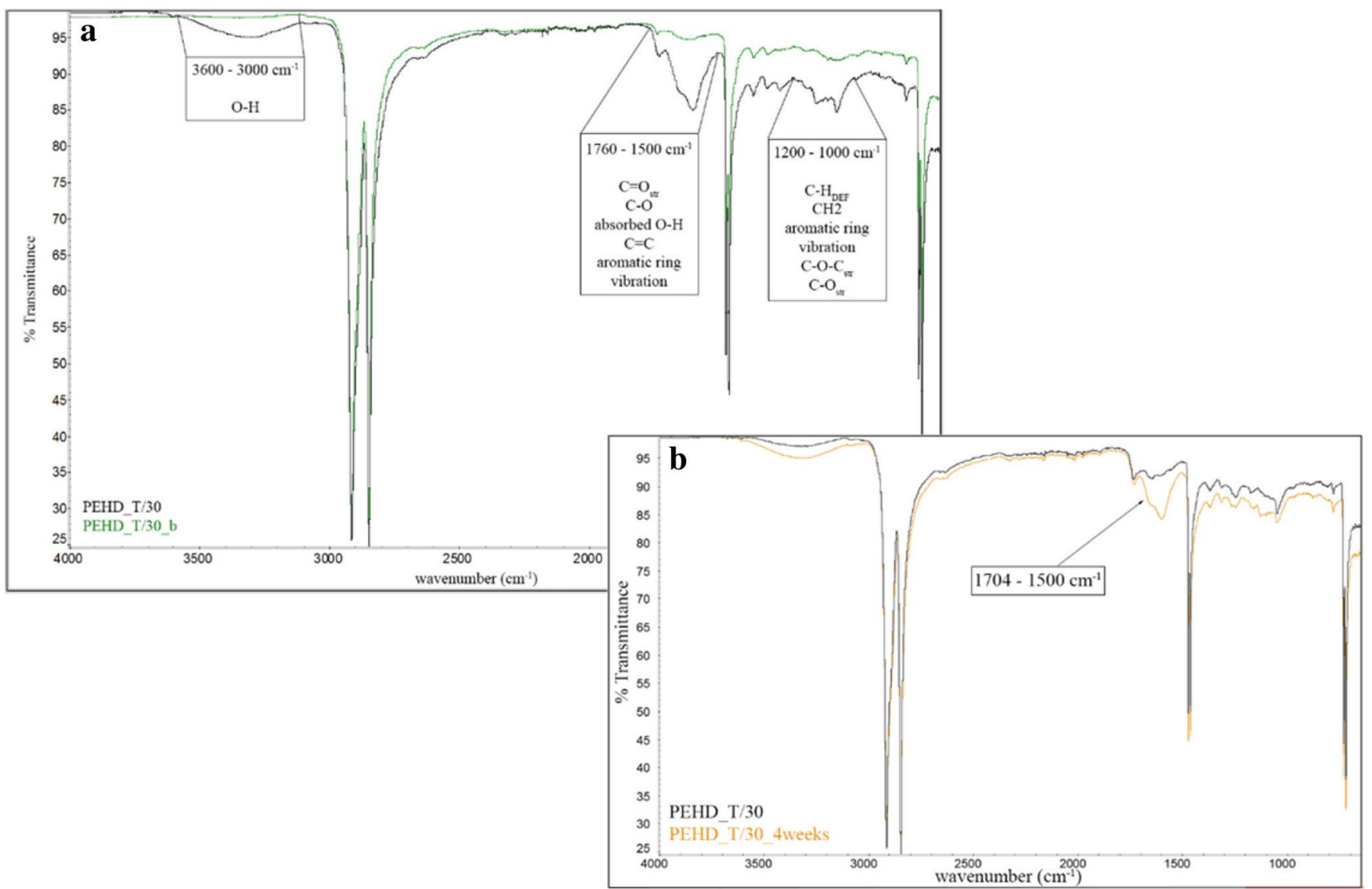

Fig. 4 FTIR/ATR spectrum of PEHD_T/30 (series I made directly after manufacture black curve) and a after 2 weeks of microbial cultivation (green curve), b 4 weeks after preparation (series II orange curve). (Color figure online) 
the changes are primarily observed at $1704-1500 \mathrm{~cm}^{-1}$. What is more, contrary to the wood flour composites as described previously, the study for the materials after 2 weeks of exposure to the microbial culture of $A$. niger showed a drop in the intensity of that band (Table 2, column 2 and 3) in comparison with the initial data. This suggests that the observed unstable fungistatic effect is associated with the varying amounts of the volatile fraction contained in the conifer needles.

In order to clarify whether this effect is associated with the loss (volatilisation, dissolution in a microbial medium) of some part of extractives present in the conifer needles, the composites were analysed by FTIR/ATR after 4 weeks from their preparation (series II). In this case, a reduction was observed in the intensity of the at $1700-1500 \mathrm{~cm}^{-1}$ versus initial data (Fig. 4b; Table 2 column 2 and 4 ) as well. The volatile fraction of extractives mainly consists of mono- or sesquiterpenes (isoprene units) [45, 46], and therefore the observed changes may result from a change in the intensity of the band associated with the vibration of $\mathrm{C}=\mathrm{C}_{\text {str }}$. It confirms that the structural changes in the composites observed after cultivation of $A$. niger are most likely associated only with the loss of fractions that are volatile or soluble in the Czapka medium.

The studies on the composites (with conifer needles) exposed to biodegradation caused by A. niger showed that those materials offered a higher resistance than the previously described WPCs which contained conifer flour [19]. This can be accounted for by a high (initial) content of extractives in the composites and/or by a high cellulolytic activity of $A$. niger [19, 47]. Huang et al. [48] indicated in 2010 that the lignin-carbohydrate complex constitutes a barrier for accessibility to cellulose and hemicellulose, thus lowering the rate of biodegradation. However, due to the content of particular plant fillers (low amount of lignin) and their origin (coniferous), the observed effect might probably be associated with the share of extractives. In order to confirm that, the next step involved the tests for the

Table 2 Surface area of the band $1704-1500 \mathrm{~cm}^{-1}$

\begin{tabular}{llll}
\hline Sample ID & \multicolumn{2}{l}{ surface area of 1704-1500 $\mathrm{cm}^{-1}$} \\
\cline { 2 - 4 } & $\begin{array}{l}\text { Initial data } \\
\text { (series I) }\end{array}$ & $\begin{array}{l}\text { A. niger after 2 } \\
\text { weeks (series I) }\end{array}$ & $\begin{array}{l}\text { 4 weeks after } \\
\text { preparation } \\
\text { (series II) }\end{array}$ \\
\hline PEHD_T/10 & 3.28 & 0.13 & 1.40 \\
PEHD_T/30 & 3.99 & 0.45 & 1.86 \\
PEHD_T/50 & 6.88 & 3.45 & 4.26 \\
co(E-P)_S/10 & 2.18 & 0.04 & 1.00 \\
co(E-P)_S/30 & 2.28 & 0.08 & 1.24 \\
co(E-P)_S/50 & 2.39 & 0.46 & 1.39
\end{tabular}

biodegradation effectiveness of natural resins as they contain more terpenes and non-volatile fractions rich in resin acids [49].

\section{Evaluation of Fungistatic Effect of Natural Resins}

In order to choose a resin to be used in the preparation of polymer-plant composites with a the reduced susceptibility to biodegradation, a fungistatic effect was assessed for four natural resins, and namely dammar gum (mainly consists of triterpenoid resin) [50, 51], galbanum (mainly consists of monoterpene hydrocarbons) [52], rosin (mainly consists of resin acids) [53] and sandarac (mainly consists of diterpenoid acids of the labdanic structure) [54].

In order to identify the threshold concentration of resin at which the mycelial growth is inhibited, the resin solutions were prepared for the study at the concentrations of $0.25 ; 0.5 ; 1 ; 3 ; 5 ; 7 ; 10$ and $30 \%$, in which 5 -cm paper discs were soaked. The control samples consisted of paper discs not soaked in the resin solution and paper discs soaked in the solvents used to prepare the resin solutions. The fungistatic effect was assessed by monitoring the growth of the mycelium on the surfaces of the discs saturated with the resin solutions.

After the first 3 days, inhibition of the growth of A. niger was observed for three resins, i.e. dammar gum (conc. of $10 \%$ ), colophony (cons. of 7\%) and sandarac (conc. of 5\%) (Fig. 5). After 2 weeks, the highest limitation of the growth of the mycelium was observed for sandarac. This effect was visible already at the concentration of $7 \%$. However, the inhibiting effect on the growth of the mycelium on the surface of the disc soaked in the sandarac solution was significant at the concentration of $10 \%$, and the total inhibition was observed for the $30 \%$ solution of that resin. In the case of colophony, the fungistatic effect was only found for the sample saturated with the $30 \%$ solution.

The results of these experiments showed that two of the four selected natural resins: rosin and sandarac, indicated the total inhibition of growth of the A niger mycelium in the presence of their $30 \%$ solutions. Presumably, the fungistatic effect is associated with a high proportion of rosin acids and terpene compounds which contain more isoprene units. The resins containing mainly terpenes, composed of three isoprene units (di-, triterpenes) showed the fungistatic effects. No inhibition of mycelial growth was observed for galbanum which mainly consists of monoterpenes $[55,56]$.

The resistance of the materials that contain coniferous fillers (conifer wood flour, conifer needles) grows with the increasing content of extractives. The concentration of non-volatile extractives is clearly higher in natural resins. For this reason in the next stage of our research it was decided to enhance the resistance of CNPCs through the addition of a selected natural resin rich, inter alia in more 


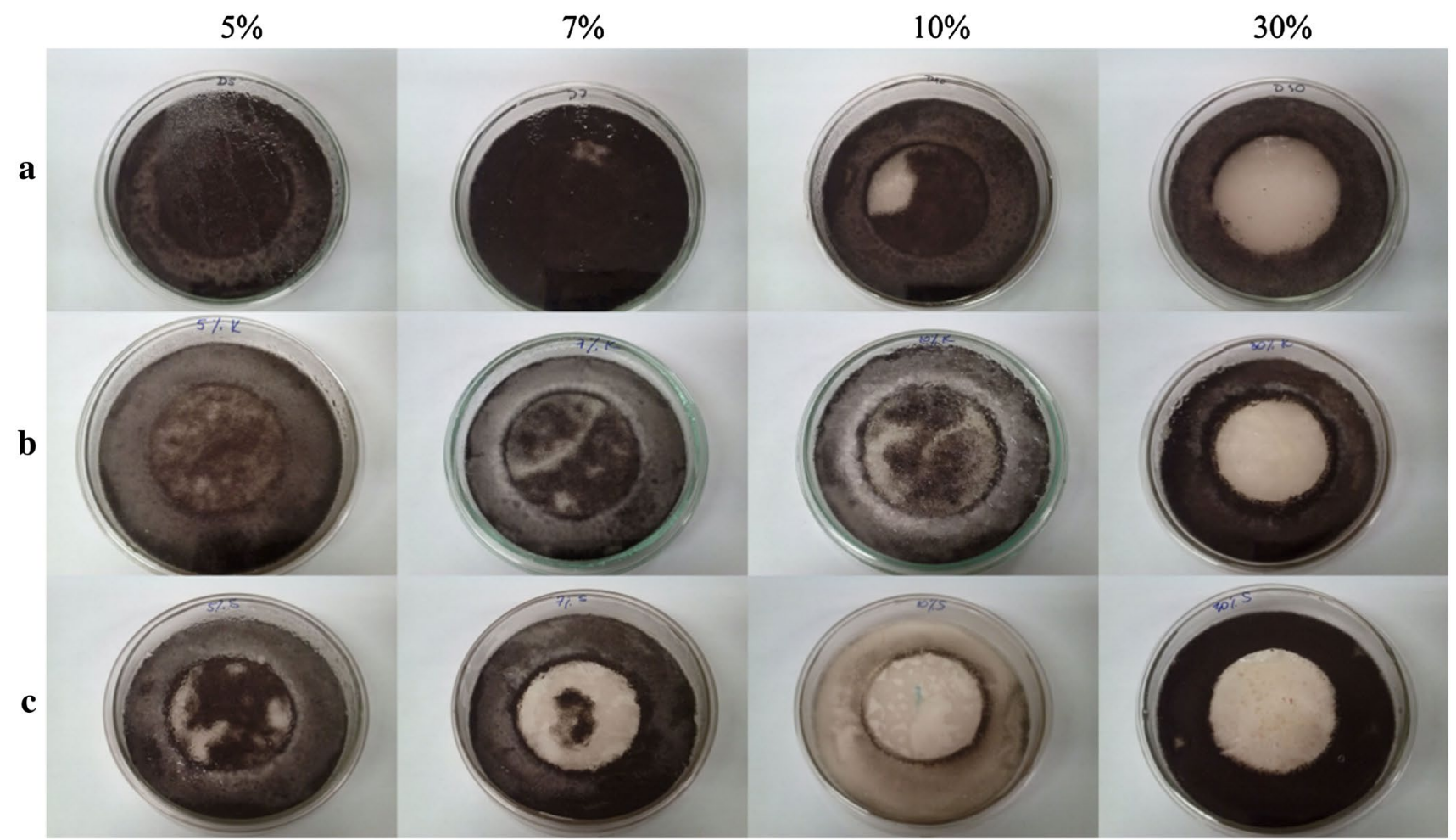

Fig. 5 Mycelial growth after 3 days of growth on a paper disc with a 5, 7, 10 or 30\% solution of a dammar, b colophony (rosin) or $\mathbf{c}$ sandarac. (Color figure online)

stable resin acids (compounds with a potential fungistatic effect). What is more, a few studies describe the ability of some microorganisms (bacterial species like Pseudomonas, Burkholderia, Cupriavidus or fungal strains like Aspergillus terreus, Aspergillus flavus, Penicillium decumbens) to use individual components of resin as a sole carbon source or to biotransform particular terpene molecules [57]. For that reason, further experiments were planned to verify the resistance of the composites to the impact of the consortium of microorganisms contained in the composts. The forest compost and spent mushroom compost obtained after the culture of Agaricus bisporus were selected for those studies.

\section{Composting of PEHD Composites with Pine Needles in Forest Compost and Spent Mushroom Compost}

The commonly used mercerization process of wood fillers (i.e. treatment of plant filler material with a solution of $\mathrm{NaOH}$ ) aims at obtaining a stable form of cellulose and at removing additional ingredients such as waxes, lignins and/or extractives. That improves mechanical properties of the material containing such modified flour [58-60]. Therefore, we used composites that contained mercerized flour of pine needles (PEHD_P/50m) and composites with mercerized pine needle flour and $10 \mathrm{wt} \%$ sandarac (PEHD_P/50_mr) besides composites containing flour of pine needles (PEHD_P/30, PEHD_P/50) in the study on composting. Removal of additional substances by mercerization, and then introducing the sandarac additive was done to emphasised the effect derived from the resin used. The samples were placed for 90 days in the forest and spent mushroom composts. Due to the absence of significant differences in the properties of the control sample, i.e. PEHD, only results obtained for composites samples are presented. Observations of composted samples indicated considerable discoloration and surface cracking for samples placed in the forest compost (Fig. 6-1, 2, 3, $4,5,6 \mathrm{~b}$ ), whereas only slight discoloration and no cracks in the surface were observed for the composites placed in spent mushroom compost (Fig. 6-1, 2, 3, 4, 5, 6c). Discoloration accompanied by cracking of the sample was observed only for the samples with the $50 \mathrm{wt} \%$ content of the pine needle filler. Due to the fact that most chromophores are present in the lignin, composite discoloration may be associated with degradation of the lignin contained in the plant filler [61, 62]. The observation images of the aged samples also show the appearance of cracks on their surfaces, the intensity of which depends on the type of the plant filler and its content in the composite. 


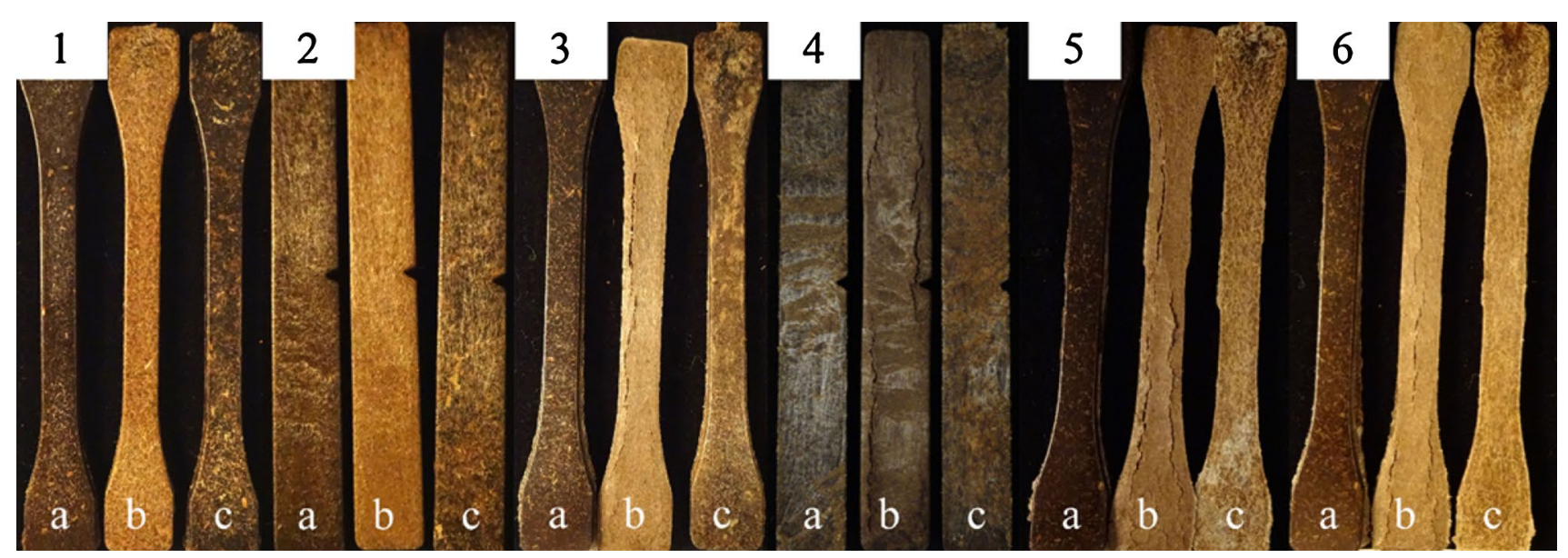

Fig. 6 Composite samples in the form of dumbbells containing $30 \mathrm{wt} \%$ (1) or $50 \mathrm{wt} \%$ (3) of pine needles, or $50 \mathrm{wt} \%$ of mercerized pine needle flour (5) or $50 \mathrm{wt} \%$ mercerized pine needle flour with the addition of $10 \mathrm{wt} \%$ sandarac (6) and beams containing $30 \mathrm{wt} \%$ (2) or $50 \mathrm{wt} \%$ of pine needles (4) before ( $a$ ) and after 90 days of composting in forest $(b)$ or spent mushroom $(c)$ compost. (Color figure online)
Fig. 7 Micrographs of the surface of PEHD_P/50 composites for samples after 90 days of composting in the forest (1) or spent mushroom (2) compost with a magnification of $100 x$

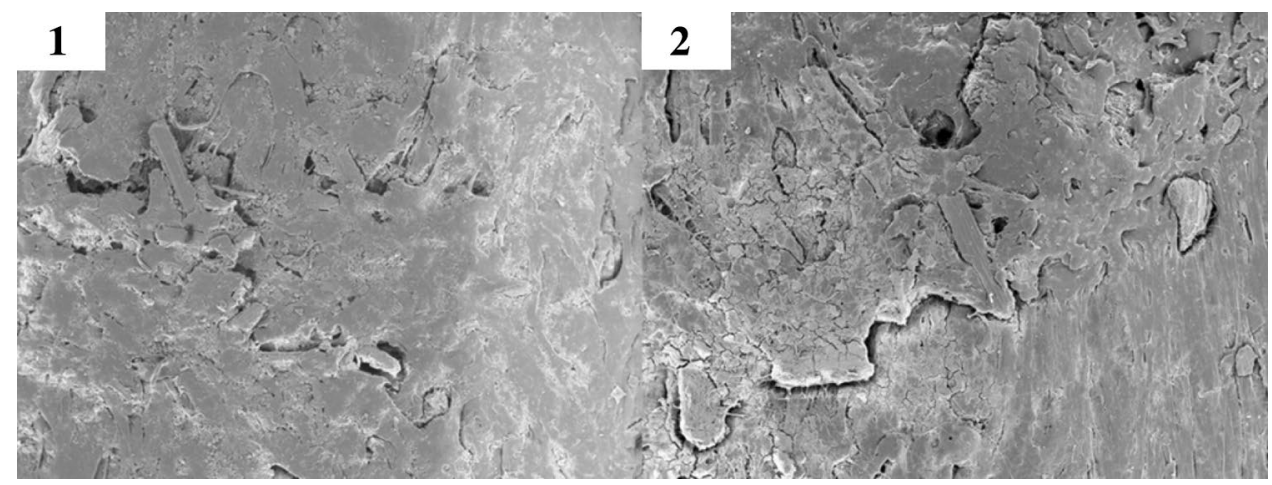

Table 3 Weight loss (\%) for tested materials after 3 months of composting in forest or spent mushroom compost ( $2 \mathrm{~mm}$ sample)

\begin{tabular}{lll}
\hline Sample ID & Weight loss $(\%)$ & \\
\cline { 2 - 3 } & Forest compost & $\begin{array}{l}\text { Spent } \\
\text { mushroom } \\
\text { compost }\end{array}$ \\
\hline PEHD & 0.0 & 0.0 \\
PEHD_P/30 & 0.2 & 0.5 \\
PEHD_P/50 & 6.1 & 1.0 \\
PEHD_P/50 m & 7.2 & 1.8 \\
PEHD_P/50mr & 3.6 & 0.4 \\
\hline
\end{tabular}

The tests on WPCs degradation processes under external weathering indicate that the cracks on the composite surfaces are typically associated with the phenomenon of water absorption that promotes deterioration of material cohesion [63] and it is highly dependent on the share of the plant filler. Therefore, as expected, a greater number of cracks was observed for the composites containing
$50 \mathrm{wt} \%$ of pine needles. Interestingly, the cracks were not observed in the composites placed in spent mushroom compost. Probably this is due to the fact that the spent mushroom compost and the forest one consist of different microbial consortia. What is more, spent mushroom compost possess a high ability to absorb water (high moisture content) [64] hence the environmental impact of this factor on the composite surface is lower.

The micrographs of the surface of the PEHD_P/50 composites, as shown in Fig. 7, indicate that the surface inhomogeneity in the form of delamination and losses, as well as pieces of mycelium hyphae are observed for both samples placed in the forest compost and those in spent mushroom compost. Similar dependences were obtained for PEHD_P/50m and PEHD_P/50mr. In comparison with the above mentioned micrographs of composite surfaces after exposure to the microbial culture on the liquid Czapek medium, large surface destruction was reported. Therefore, an analysis was conducted concerning the weight loss of samples and changes in their mechanical properties and performance. 
The weight losses of the analysed samples are summarised in Table 3. The samples placed in the forest or spent mushroom compost were characterised by the weight loss which is increasing with the growing degree of filling. The results obtained for PEHD_P/30, regardless of the type of the compost medium, were similar (0.2-0.5\% weight loss). In turn, for PEHD_P/50 and PEHD_P/50m, greater weight losses were found for the samples placed in the forest compost than in the spent mushroom one. Interestingly, PEHD_P/50mr also revealed a greater weight gain for the sample which was kept in the forest compost. However, in this case the weight gain for the sample was by $41 \%$ lower than for PEHD_P/50 and by 50\% smaller than for PEHD_P/50m after incubation in the forest compost, and by 60 and $78 \%$ smaller than for the corresponding samples after composting in spent mushroom compost. That indicates that the applied resin additive can delay biodegradation. It is confirmed by an earlier assumption relating to the ability to use natural resins as additives with a potential to inhibit biodegradation of composites. This also demonstrates that more intense decomposition processes of the tested materials were observed in the forest compost medium and it is consistent with the above-described differences in physical changes of samples.

Figure $8 \mathrm{a}-\mathrm{c}$ show the changes in the properties of PEHD_P/50, PEHD_P/50m and PEHD_P/50mr (tensile strength, impact strength, MFR). First of all, it was observed that the use of the resin additive did not cause any change in tensile strength. However, the impact strength of the composite grew a bit, thus increasing the MFR-value at the same time. It shows that the resin additive acts also as a lubricant, which could lead to the improvement of processing parameters. After composting, the changes were first of all found in the tensile strength values, where incubation of the samples especially in the forest compost resulted in deterioration of this parameter in relation to the control samples (non-composted) [65, 66]. This is due to deterioration of the material cohesion at the polymer matrix/ plant filler interface in connection with the appearance of cavities on the surface and/or inside the sample [67, 68]. This once again confirms the above observations, show the higher rate of decomposition of the analysed samples in the forest compost. However, no significant changes in the values were found for the impact strength and MFR.

In order to confirm the observed changes, the tested materials were analysed for their chemical compositions (FTIR/ATR). It results from Fig. 9 that due to incubation of the composites in the forest compost or spent mushroom compost the intensity of bands typical for the plant filler was changed, especially for composites with $50 \mathrm{wt} \%$ filler. In all types of composites that contained $50 \mathrm{wt} \%$ of the fillers, increased bands are observed at $3600-3000 \mathrm{~cm}^{-1}$. These changes are similar regardless of
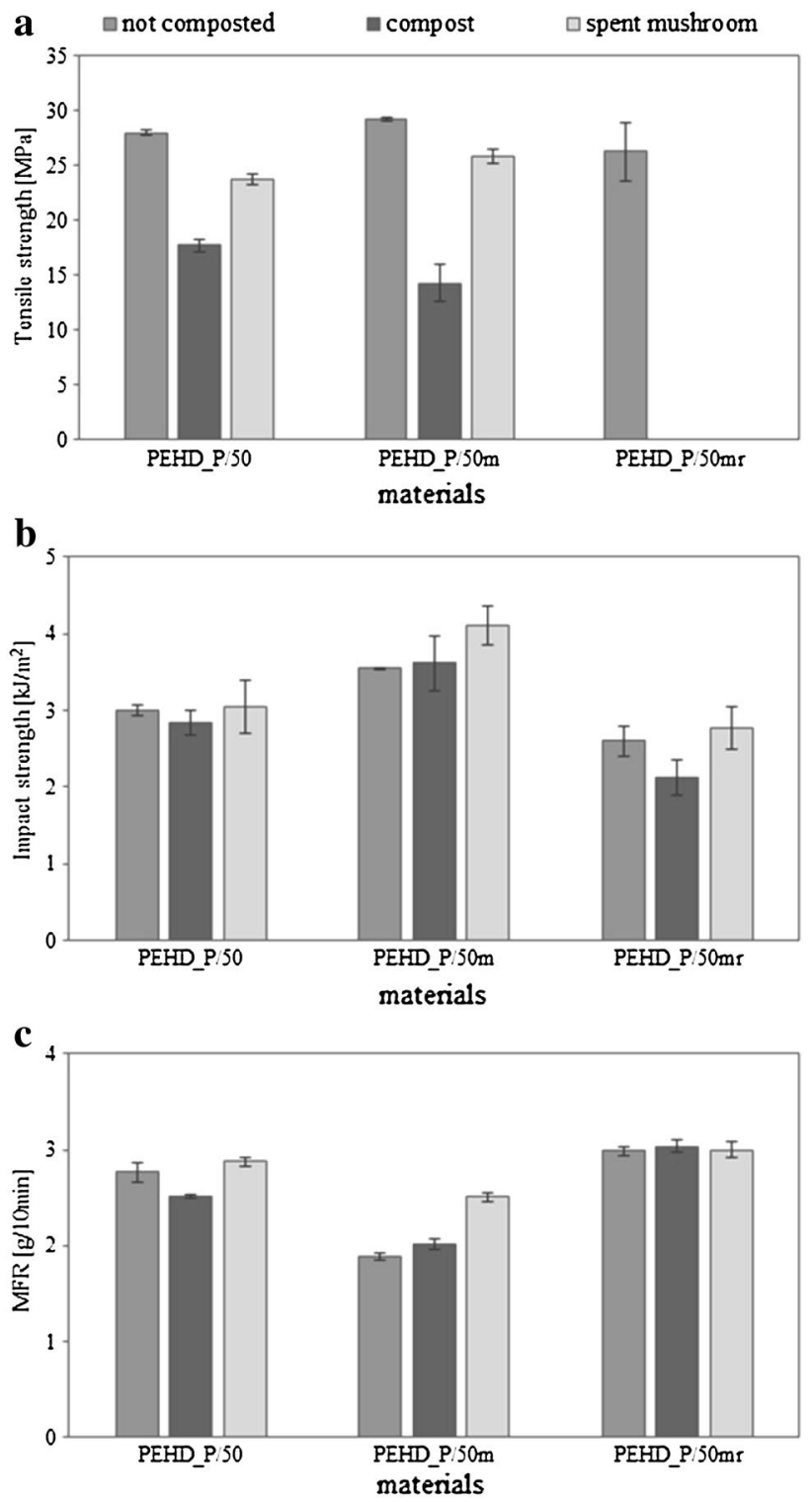

Fig. 8 Properties of composites before and after 90 days of composting in forest or spent mushroom compost, a tensile strength, $\mathbf{b}$ impact strength, c MFR

the type of the substrate. However, differences were found in the $1774-912 \mathrm{~cm}^{-1}$ range for various composites, i.e. those with the $50 \mathrm{wt} \%$ content of unmodified flour, mercerized flour or mercerized flour with a resin additive. The changes are dependent on the conditions of the sample incubation process. For PEHD_P/50, regardless of the type of the filler, the observed increase in the intensity of the bands at $1774-1491$ and at $1186-912 \mathrm{~cm}^{-1}$ is analogous. On the other hand, in the spectrum of PEHD_50/m and PEHD_P/50mr samples composted in the forest compost, two peaks were found (at approx. 1650 and $1597 \mathrm{~cm}^{-1}$ ) in the $1774-1491 \mathrm{~cm}^{-1}$ range that is specific for the groups present in the structures of lignin. On the other hand, in 
Fig. 9 Comparison of spectrograms received for PEHD_P/30, PEHD_P/50, PEHD_P/50m and PEHD_P/50mr before (blue curve) and after 90 days of composting in forest (orange curve) or spent mushroom (black curve) compost. (Color figure online)
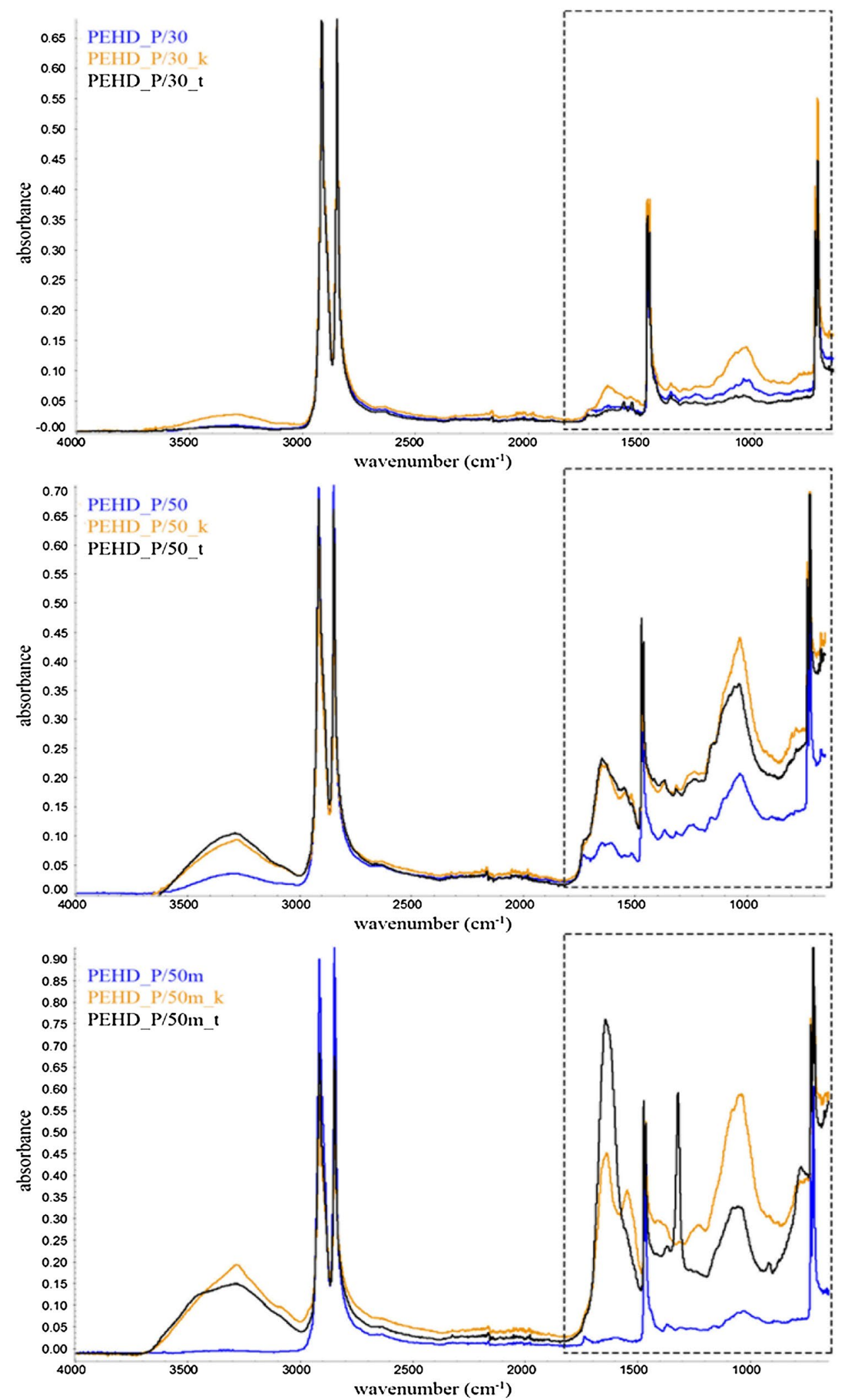
Fig. 9 (continued)

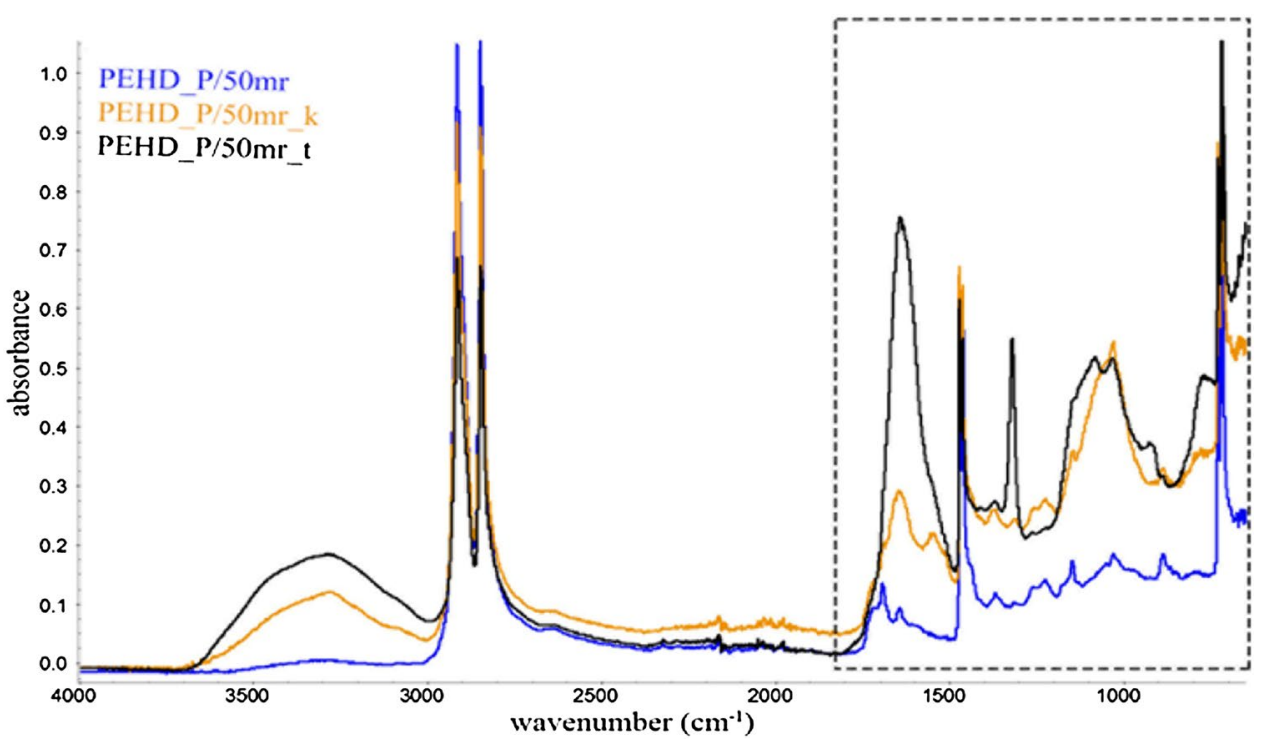

the same range of the composite spectrum after composting in spent mushroom compost, a single and broad peak was revealed together with a very clear, sharp peak at the wavenumber of $1317 \mathrm{~cm}^{-1}$, characteristic for $\mathrm{CH}_{2}$ wagging vibrations present in the molecules of cellulose and hemicellulose.

The quantitative changes of the surface area at 1774-1491 cm $\mathrm{cm}^{-1}$ (typical for lignin groups) and 1186-912 $\mathrm{cm}^{-1}$ (band specific for cellulose groups) [44, 69, 70] are presented in Table 4. As expected, the noncomposted samples showed the increase in the intensity of the 1774-1491 $\mathrm{cm}^{-1}$ band compared to composites with mercerized flour and $10 \mathrm{wt} \%$ of sandarac, caused by a high proportion of resin acids in the sandarac. Furthermore, as expected, mercerized flour was characterized by lower contents of lignins and additives, thus causing a clear decrease of the $1774-1491 \mathrm{~cm}^{-1}$ band in relation to the sample which contained unmodified flour. For PEHD_P/50 and PEHD_P/50mr samples composted in the forest compost, a similar increase in the intensity of the $1774-1491 \mathrm{~cm}^{-1}$ band was found, and a higher than twofold growth in the intensity of this band for PEHD_P/50m. Similar changes were found in the $1186-912 \mathrm{~cm}^{-1}$ range, where the increase in the band intensity for PEHD_P/50m compared to the baseline was proportionally highest in the group of test materials. This is probably a consequence of the removed protective barrier in the form of lignin and other additives through mercerization. As a result, the most intense decomposition processes of cellulose and hemicellulose (oxidation, hydrolysis) are observed for PEHD_P/50m. That is also confirmed by sharpening of the peak at a wave number of $1597 \mathrm{~cm}^{-1}$ (that is characteristic for lignin).

The analysed of changes in the samples after composting in spent mushroom compost are indicative for a completely different mechanism of interaction of the microorganisms contained in it. In this case, a similar and almost three times higher increase in the intensity of the 1774-1491 $\mathrm{cm}^{-1}$ band in relation to the PEHD_P/50 was found for PEHD_P/50m and PEHD_P/50mr. On the other hand, considerably smaller differences in the intensity of the bands was observed in the $1186-912 \mathrm{~cm}^{-1}$ range for the compared samples. It was accompanied by

Table 4 Changes in surface area of the band 1774-1491 and 1186-912 $\mathrm{cm}^{-1}$ after composting

\begin{tabular}{|c|c|c|c|c|c|c|}
\hline \multirow[t]{3}{*}{ Sample ID } & \multicolumn{6}{|c|}{ Surface area of the band } \\
\hline & \multicolumn{3}{|l|}{$1774-1491 \mathrm{~cm}^{-1}$} & \multicolumn{3}{|l|}{$1186-912 \mathrm{~cm}^{-1}$} \\
\hline & Not composted & Forest compost & $\begin{array}{l}\text { Spent mushroom } \\
\text { compost }\end{array}$ & Not composted & Forest compost & $\begin{array}{l}\text { Spent } \\
\text { mushroom } \\
\text { compost }\end{array}$ \\
\hline PEHD_P/30 & 3.3 & 5.7 & 2.4 & 3.2 & 7.9 & 1.6 \\
\hline PEHD_P/50 & 7.5 & 25.0 & 24.1 & 10.8 & 30.7 & 22.3 \\
\hline PEHD_P/50m & 1.1 & 53.1 & 67.6 & 3.1 & 45.1 & 20.0 \\
\hline PEHD_P/50mr & 6.1 & 20.2 & 71.0 & 3.8 & 24.1 & 32.8 \\
\hline
\end{tabular}


the occurrence of the peak spectrum characteristic for cellulose $\left(1317 \mathrm{~cm}^{-1}\right)$. Biodegradation of lignocellulose (derived from the plant filler) of the composites results from collaboration of some fungi, actinomycetes and bacteria [48, 71-73]. The observed differences can be indicative for different proportions of cellulolytic and ligninolytic microorganisms which have the ability of decomposing resin acids in both substrates. In particular that in the spent mushroom compost obtained after the culture of A. bisporus Singh et al. have identified mainly species of filamentous fungi (Aspergillus fumigatus) and bacteria (Bacillus spp. and Sphingobacterium spp.) produced cellulolytic and xylolytic enzymes [74].

Summing up, it is worth paying attention to a better cellulolytic activity of the microorganisms which are present in the forest compost; greater weight loss in samples, cracking and deterioration of mechanical properties, the changes chemical composition reflected in structural features of the samples incubated in the forest compost. Moreover, it might be concluded on the basis of the structural analysis that the mechanism of interaction of microorganisms contained in the spent mushroom compost and in the forest compost is different. The impact of the microorganisms contained in the forest compost results in the accelerated cellulose decomposition process. The resin addition inhibited biodegradation of cellulose as compared with the composite which contained mercerized flour without the resin addition. Nothing similar was found in the case of samples which were composted in spent mushroom compost. This may be indicative for the increased activity of the cellulolytic microorganisms in the forest compost. On the other hand, it may also demonstrate that the microorganisms present in the spent mushroom compost show the enhanced ability of decomposing the substances contained in the resin.

\section{Conclusion}

The 2-week studies on resistance to biodecomposition of composites with conifer needles conducted against a single strain of A. niger, and 90-day test against a consortium of microorganisms present in the forest compost, or in spent mushroom compost, showed that the extractives and lignin contained in the plant filler play a key role in increasing said resistance. The studies on composting showed that the addition of the sources of natural resin established a protective barrier against the impact of microorganisms with a high cellulolytic activity. What is worth emphasizing, this phenomenon was observed in laboratory experiments which simulated the natural processes. Some potential for CNPCs to be recycled commercially was thus identified.
Open Access This article is distributed under the terms of the Creative Commons Attribution 4.0 International License (http:// creativecommons.org/licenses/by/4.0/), which permits unrestricted use, distribution, and reproduction in any medium, provided you give appropriate credit to the original author(s) and the source, provide a link to the Creative Commons license, and indicate if changes were made.

\section{References}

1. Faruk O, Błędzki AK, Fink HP, Sain M (2012) Biocomposites reinforced with natural fibers: 2000-2010. Prog Polym Sci 37:1552-1596. doi:10.1016/j.progpolymsci.2012.04.003

2. Mohammed L, Ansari MNM, Pua G, Jawaid M, Islam MS (2015) A review on natural fiber reinforced polymer composite and its applications. Int J Polym Sci. doi:10.1155/2015/243947

3. Gu JD (2003) Microbiological deterioration and degradation of synthetic polymeric materials: recent research advances. Int Biodeterior Biodegrad 52(2):69-91

4. Gilan I, Hadar Y et al (2004) Colonization, biofilm formation and biodegradation of polyethylene by a strain of Rhodococcus ruber. Appl Microbiol Biotechnol 65(1):97-104

5. Fontanella S, Bonhomme $\mathrm{S}$ et al (2010) Comparison of the biodegradability of various polyethylene films containing pro-oxidant additives. Polym Degrad Stab 95(6):1011-1021

6. Rajandas H, Parimannan S et al (2012) A novel FTIR-ATR spectroscopy based technique for the estimation of low-density polyethylene biodegradation. Polym Test 31(8):1094-1099

7. Chiellini E, Corti A et al (2003) Biodegradation of thermallyoxidized, fragmented low-density polyethylenes. Polym Degrad Stab 81(2):341-351

8. Gu JD, Roman M et al (1998) The role of microbial biofilms in deterioration of space station candidate materials. Int Biodeterior Biodegrad 41(1):25-33

9. Lobelle D, Cunliffe M (2011) Early microbial biofilm formation on marine plastic debris. Mar Pollut Bull 62(1):197-200

10. Gu JD, Lu C et al (1997) Fiber-reinforced polymeric composites are susceptible to microbial degradation. J Ind Microbiol Biotechnol 18(6):364-369

11. Gu JD, Ford T et al (1996) Microbial growth on fiber reinforced composite materials. Int Biodeterior Biodegrad 37(3-4):197-204

12. Gu JD (2007) Microbial colonization of polymeric materials for space applications and mechanisms of biodeterioration: a review. Int Biodeterior Biodegrad 59(3 SPEC. ISS.):170-179

13. Gu JD, Yang S et al (1994) Effect of environmental parameters on the degradability of polymer films in laboratory-scale composting reactors. J Environ Polym Degrad 2(2):129-135

14. Gu JD, Coulter S et al (1993) A respirometric method to measure mineralization of polymeric materials in a matured compost environment. J Environ Polym Degrad 1(4):293-299

15. Gu JD, Eberiel DT et al (1993) Cellulose acetate biodegradability upon exposure to simulated aerobic composting and anaerobic bioreactor environments. J Environ Polym Degrad 1(2):143-153

16. Gu JD, Eberiel D et al (1993) Degradation and mineralization of cellulose acetate in simulated thermophilic compost environments. J Environ Polym Degrad 1(4):281-291

17. H'ng PS, Lee AN, Hang CM, Lee SH, Khalina A, Paridah MT (2011) Biological durability of injection moulded wood plastic composite boards. J Appl Sci 11:384-388. doi:10.3923/ jas.2011.384.388

18. Fabiyi JS, McDonald AG, Morrell JJ, Freitag C (2011) Effects of wood species on durability and chemical changes of fungal 
decayed wood plastic composites. Composites Part A 42:501510. doi:10.1016/j.compositesa.2011.01.009

19. Barton-Pudlik J, Czaja K, Grzymek M, Lipok J (2017) Evaluation of wood-polyethylene composites biodegradability caused by Filamentous fungi. Int Biodeter Biodegrad 118C:10-18. doi:10.1016/j.ibiod.2017.01.014

20. Lomelí-Ramírez MG, Ochoa-Ruiz HG, Fuentes-Talavera FJ, Garcia S, Cerpa-Gallegos MA, Silva-Guzmán JA (2009) Evaluation of accelerated decay of wood plastic composites by Xylophagus fungi. Int Biodeterior Biodegrad 63:1030-1035. doi:10.1016/j.ibiod.2009.08.002

21. Xu K, Feng J, Zhong T, Zheng Z, Chen T (2015) Effects of volatile chemical components of wood species on mould growth susceptibility and termite attack resistance of wood plastic composites. Int Biodeter Biodegr 100:106-115. doi:10.1016/j. ibiod.2015.02.002

22. Košíková B, Sláviková E, Sasinková V, Kačík F (2006) The use of various yeast strains for removal of pine wood extractive constituents. Wood Res 51:47-54

23. Räisänen T (2013) Basic chemical composition of the biomass components of pine, spruce and birch. http://www.biofuelregion. se/UserFiles/file/Forest\%20Refine/1_2_IS_2013-01-31_Basic_ chemical_composition.pdf. Accessed 21 July 2016

24. Berg B, Hannus K, Popoff T, Theander O (1980) Chemical components of scots pine needles and needle litter and inhibiotion of fungal species by extractives. Ecol Bull 32:391-400

25. Sharma N, Tandon D, Gupta R, Kumar S (2011) Evaluation of different pretreatments to enhance degradation of pine needles by Aspergillus niger $\mathrm{F} 7$ under solid state fermentation. J Sci Ind Res 70:778-783

26. Dorado J, Van Beek TA, Claassen FW, Sierra-Alvarez R (2001) Degradation of lipophilic wood extractive constituents in Pinus sylvestris by the white-rot fungi Bjerkandera sp. and Trametes versicolor. Wood Sci Technol 35:117-125. doi:10.1007/ s002260000077

27. Barton-Pudlik J, Czaja K (2016) Conifer needles as thermoplastic composite fillers: structure and properties. BioResources 11:6211-6231. doi:10.15376/biores.11.3.6211-6231

28. Flemming HC (2010) Biodeterioration of synthetic materials-A brief review. Mater Corros 61:986-992. doi:10.1002/ maco. 201005837

29. Catto AL, Rosseto ES, Reck MA, Rossini K, da Silveira RM, Santana RMC (2014) Growth of white rot fungi in composites produced from urban plastic waste and wood. Macromol Symp 344:33-38. doi:10.1002/masy.201300216

30. Zajchowski S, Ryszkowska J (2009) Wood-polymer composites-General characteristics and their preparation from waste materials. Polimery 54:754-762

31. Ashori A, Kiani H, Mozaffari SA (2011) Mechanical properties of reinforced polyvinyl chloride composites: effect of filler form and content. J Appl Polym Sci 120:1788-1793. doi:10.1002/ app. 33378

32. Savluchinske-Feio S, Curto MJM, Gigante B, Roreir JC (2006) Antimicrobial activity of resin acid derivatives. Appl Microbiol Biotechnol 72(3):430-436. doi:10.1007/s00253-006-0517-0

33. Trapp S, Croteau R (2001) Defensive resin biosynthesis in conifers. Annu Rev Plant Biol 52:689-724. doi:10.1146/annurev. arplant.52.1.689

34. Ulukanli Z, Karabörklü S, Bozok F, Ates B, Erdogan S, Cenet M, Karaaslan MG (2014) Chemical composition, antimicrobial, insecticidal, phytotoxic and antioxidant activities of Mediterranean Pinus brutia and Pinus pinea resin essential oils. Chin J Nat Med 12:0901-0910. doi:10.1016/S1875-5364(14)60133-3

35. Tiitta M, Tomppo L, Järnström H, Viitanen, H (2009) Spectral and chemical analyses of mould development on Scots pine heartwood. Eur J Wood Prod 67:151-158. doi:10.1007/ s00107-008-0298-5

36. Franich RA, Gadgil PD, Shain L (1983) Fungistaxic effects of Pinus radiata needle epicuticular fatty and resin acids on Dothistroma pini. Physiol Plant Pathol 23:183-195. doi:10.1016/0048-4059(83)90001-2

37. Savluchinske-Feio S, Carlos Roseiro J, Gigante B, Curto M (1997) Method on multiwell plates for the evaluation of the antimicrobial activity of resin acid derivatives. J Microbiol Methods 28:201-206. doi:10.1016/S0167-7012(97)00982-2

38. Savluchinske-Feio S, Gigante B, Roseiro J, Curto M (1999) Antimicrobial activity of diterpene resin acid derivatives. J Microbiol Methods 35:201-206. doi:10.1016/S0167-7012(98)00117-1

39. Savluchinske-Feio S, Franca S, Silva AM, Gigante B, Roseir JC, Curto M (2002) Antimicrobial activity of methyl cis-7-oxo deisopropyldehydroabietate on Botrytis cinerea and Lophodermium seditiosum: ultrastructural observations by transmission electron microscopy. J Appl Microbiol 93:765-771. doi:10.1046/j.1365-2672.2002.01744.x

40. Kopper BJ, Illman BL, Kersten PJ, Klepzig KD, Raffa KF (2005) Effects of diterpene acids on components of a conifer bark beetle-fungal interaction: tolerance by Ips pini and sensitivity by its associate Ophiostoma ips. Environ Entomol 34:486-493. doi:10.1603/0046-225X-34.2.486

41. Söderberg TA, Holm S, Gref R, Hallmans G (1991) Antibacterial effects of zinc oxide, rosin, and resin acids with special reference to their interactions. Scand J Plas Reconstr Surg Hand Surg 25:19-24. doi:10.3109/02844319109034918

42. Mohebby B (2005) Attenuated total reflection infrared spectroscopy of white-rot decayed beech wood. Intl Biodeter Biodegrn 55:247-251. doi:10.1016/j.ibiod.2005.01.003

43. Popescu CM, Popescu MC, Vasile C (2010) Structural changes in biodegraded lime wood. Carbohydr Polym 79:362-372. doi:10.1016/j.carbpol.2009.08.015

44. Fan M, Dai D, Huang B (2012) Fourier transform infrared spectroscopy for natural fibres, fourier transform-materials analysis, Dr Salih Salih (ed), InTech, doi:10.5772/35482. http://www. intechopen.com/books/fourier-transform-materials-analysis/fourier-transform-infrared-spectroscopy-for-natural-fibres. Accessed 18 July 2016

45. Isidorov VA, Smolewska M, Purzyńska-Pugacewicz A, Tyszkiewicz Z (2010) Chemical composition of volatile and extractive compounds of pine and spruce leaf litter in the initial stages of decomposition. Biogeosciences 7:2785-2794. doi:10.5194/ bg-7-2785-2010

46. Jun Y, Lee SM, Ju HK, Kim YS (2016) Comparison of the profile and composition of volatiles in coniferous needles according to extraction methods. Molecules 21:363. doi:10.3390/ molecules21030363

47. Hrmová M, Biely P, Vršanská M (1989) Cellulose- and xylan-degrading enzymes of Aspergillus terreus and Aspergillus niger. Enzyme Microbl Technol 11:610-616. doi:10.1016/0141-0229(89)90090-2

48. Huang DL, Zeng GM, Feng CL, Hu S, Lai C, Zhao MH, Su FF, Tang L, Liu HL (2010) Changes of microbial population structure related to lignin degradation during lignocellulosic waste composting. Bioresour Technol 101:4062-4067. doi:10.1016/j. biortech.2009.12.145

49. Wilbon PA, Chu F, Tang C (2013) Progress in renewable polymers from natural terpenes, terpenoids, and rosin. Macromol Rapid Commun 34:8-37. doi:10.1002/marc.201200513

50. Mills JS, Werner AEA (1955) The chemistry of dammar resin. J Chem Soc (Resumed). doi:10.1039/jr9550003132

51. Vahur S, Teearu A, Haljasorg T, Burk P, Leito I, Kaljurand I (2012) Analysis of dammar resin with MALDI-FT-ICR-MS and 
APCI-FT-ICR-MS. J Mass Spectrom 47:392-409. doi:10.1002/ jms.2971

52. Mortazaienezhad F, Sadeghian MM (2006) Investigation of compounds from galbanum (Ferula gummosa) boiss. Asian J Plant Sci 5:905-906. doi:10.3923/ajps.2006.905.906

53. Gören AC, Bilsel G, Oztürk AH, Topcu G (2010) Chemical composition of natural colophony from Pinus brutia and comparison with synthetic colophony. Nat Prod Commun 5:1729-1732

54. Kononenko I, de Viguerie L, Rochut S, Walter Ph (2016) Qualitative and quantitative studies of chemical composition of sandarac resin by GC-MS. Environ Sci Pollut. doi:10.1007/ s11356-016-7261-5

55. Termentzi A, Fokialakis N, Skaltsounis AL (2011) Natural resins and bioactive natural products thereof as potential anitimicrobial agents. Curr Pharm Design 17:1267-1290. doi:10.2174/138161211795703807

56. Kusumoto N, Shibutani S (2015) Evaporation of volatiles from essential oils of Japanese conifers enhances antifungal activity. J Essent Oil Res 27:380-394. doi:10.1080/10412905.2015.104599 3

57. Vilanova C, Marín M Baixeras J, Lattore A, Porcar M (2014) Selecting microbial strains from pine tree resin: biotechnological applications from a terpene world. PLoS ONE. doi:10.1371/ journal.pone.0100740

58. Kaith BS, Singha AS, Kumar S, Kalia S (2008) Mercerization of flax fiber improves the mechanical properties of fiber-reinforced composites. Int J Polym Mater 57:54-72. doi:10.1080/00914030701328843

59. Kabir MM, Wang H, Lau K, Cardona F (2012) Chemical treatments on plant-based natural fibre reinforced polymer composites: an overview. Composites Part B 43:2883-2892. doi:10.1016/j.compositesb.2012.04.053

60. Borysiak S (2013) Fundamental studies on lignocellulose/polypropylene composites: effects of wood treatment on the transcrystalline morphology and mechanical properties. J Appl Polym Sci 127:1309-1322. doi:10.1002/app.37651

61. Lim SH, Lee YH, Kang HW (2013) Efficient recovery of lignocellulolytic enzymes of spent mushroom compost from oyster mushrooms, Pleurotus spp., and potential use in dye decolorization. Mycobiology 41:214-220. doi:10.5941/ MYCO.2013.41.4.214

62. Homkhiew C, Ratanawilai T, Thongruang W (2014) Effects of natural weathering on the properties of recycled polypropylene composites reinforced with rubberwood flour. Ind Crops Prod 56:52-59. doi:10.1016/j.indcrop.2014.02.034
63. Fabiyi JS, McDonald AG, Wolcott MP, Griffiths P (2008) Wood plastic composites weathering: visual appearance and chemical changes. Polym Degrad Stab 93:1405-1414. doi:10.1016/j. polymdegradstab.2008.05.024

64. Zhang L, Sun X (2014) Changes in physical, chemical, and microbiological properties during the two-stage co-composting of green waste with spent mushroom compost and biochar. Bioresour Technol 171:274-284. doi:10.1016/j.biortech.2014.08.079

65. Fakhrul T, Islam MA (2013) Degradation behavior of natural fiber reinforced polymer matrix composites. Procedia Eng 56:795-800. doi:10.1016/j.proeng.2013.03.198

66. Hazarika A, Mandal M, Maji TK (2014) Dynamic mechanical analysis, biodegradability and thermal stability of wood polymer nanocomposites. Compos Part B 60:568-576. doi:10.1016/j. compositesb.2013.12.046

67. Luo S, Netravali AN (2003) A study of physical and mechanical properties of poly(hydroxybutyrate-co-hydroxyvalerate) during composting. Polym Degrad Stab 80:59-66. doi:10.1016/ S0141-3910(02)00383-X

68. Sedlarik V, Saha N, Saha P (2006) Lactose-filled composites of metallocene linear low-density polyethylene and their degradation in the composting environment. Polym Degrad Stab 91:2039-2045. doi:10.1016/j.polymdegradstab.2006.02.002

69. Tomak ED (2014) Changes in chemical composition of decayed Scots pine and beech wood. Sci Eng Compos Mater 21:589-595. doi:10.1515/secm-2013-0180

70. Catto AL, Montagna LS, Santana RMC (2015) Abiotic and biotic degradation of post-consumer polypropylene/ethylene vinyl acetate: wood flour composites exposed to natural weathering. Polym Compos. doi: $10.1002 / \mathrm{pc} .23615$

71. Ball AS, Jackson AM (1995) The recovery of lignocellulosedegrading enzymes from spent mushroom compost. Bioresour Technol 54:311-314. doi:10.1016/0960-8524(95)00153-0

72. Tiquia SM, Wan JHC, Tam NFY (2002) Microbial population dynamics and enzyme activities during composting. Compost Sci Util 10:150-161

73. Zhu HJ, Sun LF, Zhang YF, Zhang XL, Qiao JJ (2012) Conversion of spent mushroom substrate to biofertilizer using a stresstolerant phosphate-solubilizing Pichia farinose FL7. Bioresour Technol 111:410-416. doi:10.1016/j.biortech.2012.02.042

74. Singh R, Ahlawat OP, Rajor A (2012) Identification of the potential of microbial combinations obtained from spent mushroom cultivation substrates for use in textile effluent decolorization. Bioresour Technol 125:217-225. doi:10.1016/j. biortech.2012.08.093 